\title{
Article \\ A Longitudinal Study of Episodic and Semantic Autobiographical Memory in aMCI and Alzheimer's Disease Patients
}

\author{
Juan C. Meléndez ${ }^{1, *(1)}$, Alfonso Pitarque ${ }^{2}$, Iraida Delhom ${ }^{3}{ }^{-}$, Elena Real ${ }^{1}$, Mireia Abella ${ }^{1}$ \\ and Encarnación Satorres ${ }^{1}$ (D)
}

1 Department of Developmental and Educational Psychology, Faculty of Psychology, University of Valencia, Av. Blasco Ibañez 21, ES 46010 Valencia, Spain; erecom@alumni.uv.es (E.R.); miafer2@alumni.uv.es (M.A.); Encarna.Satorres@uv.es (E.S.)

2 Department of Methodology of the Behavioral Sciences, Faculty of Psychology, University of Valencia, Av. Blasco Ibañez 21, ES 46010 Valencia, Spain; Luis.A.Pitarque@uv.es

3 Department of Psychology, Faculty of Psychology, Universidad Internacional de Valencia, Pintor Sorolla 21, ES 46002 Valencia, Spain; iraida.delhom@campusviu.es

* Correspondence: melendez@uv.es; Tel.: +34-96-398-3844

Citation: Meléndez, J.C.; Pitarque, A.; Delhom, I.; Real, E.; Abella, M.; Satorres, E. A Longitudinal Study of Episodic and Semantic

Autobiographical Memory in aMCI and Alzheimer's Disease Patients. Int J. Environ. Res. Public Health 2021, 18, 6849. https://doi.org/10.3390/ ijerph18136849

Academic Editor: Paul B. Tchounwou

Received: 15 May 2021

Accepted: 24 June 2021

Published: 25 June 2021

Publisher's Note: MDPI stays neutral with regard to jurisdictional claims in published maps and institutional affiliations.

Copyright: (C) 2021 by the authors. Licensee MDPI, Basel, Switzerland. This article is an open access article distributed under the terms and conditions of the Creative Commons Attribution (CC BY) license (https:// creativecommons.org/licenses/by/ $4.0 /)$.
Abstract: Background: The main objective of this study was to analyze the evolution of autobiographical memory (both episodic and semantic) in patients with mild cognitive impairment, patients with Alzheimer's disease, and a healthy control group. We compared these groups at two time points: first, at baseline, and in a follow-up after 18 months. Method: Twenty-six healthy older adults, 17 patients with mild amnestic cognitive impairment, and 16 patients with Alzheimer's disease, matched on age and educational level, were evaluated at both time points with the Autobiographical Memory Interview. Results: The results showed significant longitudinal deterioration in episodic and semantic autobiographical memory in patients with mild cognitive impairment and in patients with Alzheimer's disease, but not in healthy older adults. Conclusions: The deterioration of episodic and semantic autobiographical memory in AD is confirmed; however, although the episodic was impaired in aMCI, a pattern that evolved toward deterioration over a period of eighteen months was observed for the semantic autobiographical memory.

Keywords: autobiographical memory; mild cognitive impairment; Alzheimer's disease

\section{Introduction}

Autobiographical memory (AM) is a type of declarative memory that refers to the personal past and allows the recovery of personal semantic data as well as incidental or episodic memories, which means bringing first-person past situations experienced into the present. It has been well established that the normal aging process is generally associated with changes in various cognitive domains, including memory, and memory impairment is the most common cognitive symptom of amnestic mild cognitive impairment (aMCI) and Alzheimer's disease (AD) [1]. However, knowledge about the progression of AM over time is scarce. The lack of research on this topic is surprising, given that changes in memory are one of the key factors in both normal aging and in cognitive pathologies experienced by older adults. These changes appear from the beginning in the course of neurodegenerative diseases, and they continue to deteriorate with the progression of disease severity [2]. Studying the progression of AM over time is an important line of research that will help us to understand the evolution of AM and the possible changes that occur in this type of memory.

$\mathrm{AM}$ is a uniquely human form of memory that moves beyond the recall of experienced events by also integrating with these memories their interpretation and personal evaluations. Autobiographical memories are rich in thoughts, emotions, and evaluations about 
what happened, and they provide explanatory frameworks that contain human intentions and motivations [3]. AM constitutes our personal history and allows us to build an identity and continuity [4].

AM brings together general knowledge from one's past (semantic memory) and from specific events (episodic memory) [5]. Semantic memory is objective memory related to accumulated knowledge of the world that has been organized conceptually, reflects our knowledge of the world, and contains generic information acquired in different contexts [6]. Episodic memory refers to the capacity to recall individual events associated with the perceptual and sensory details collected in the context of a specific time and place; the essence of this type of memory is its specificity. The main difference lies in the fact that episodic memories allow us to re-experience the event, whereas semantic memories do not involve the re-experiencing of events although they contain information that includes general knowledge.

Due to the multi-modal nature of AM retrieval, several functional domains are engaged during recollection. Two meta-analyses $[7,8]$ report that, consistent with previous reviews of AM imaging studies, nearly all the studies on AM retrieval reported an activation of the prefrontal cortex, which plays an important role in episodic memory retrieval. In addition, they point out that more than half of the AM imaging studies reported an activation in the medial temporal lobe region (MTL), and especially the hippocampus, a region that the authors identify as a core contributor to the episodic AM network.

Several authors have shown that normal aging affects the nature of episodic AM and reduces access to contextually specific details [4], whereas studies that have examined semantic memory functioning in aging indicate that it can be preserved or even facilitated in older adults [9]. Some authors even point out that older adults, on average, produce fewer episodic details but more semantic information during AM retrieval than younger adults [10].

The results with aMCI patients have shown impaired episodic AM, but contradictory results for semantic AM. At the neuroanatomical level, there is a decrease in the volume of the hippocampus and the entorhinal cortex of the medial temporal lobes of aMCI patients [11]. In fact, when atrophy occurs in these regions, this could be a sensitive predictor of progression from aMCI to $\mathrm{AD}$ [12]. Memory performance for autobiographical episodes is impaired; however, aMCI patients produce autobiographical narratives characterized by a decrease in episodic details and an increase in semantic memories [12,13], These results are consistent with studies showing that aMCI patients scored worse on memory of autobiographical incidents than healthy older adults [14,15], but better than AD patients [15]. However, personal semantic memory remains relatively preserved [12] because when the semantic autobiographical memory is not linked to a context, it is not dependent on the hippocampus. This suggests that although aMCI might be associated with impaired remote semantic memory related to impersonal information such as famous faces, it does not appear to affect autobiographical memory for personal semantic information, especially information connected to a personally relevant event [12]. In some studies, no differences were detected between the AM of healthy older adults and that of an aMCI group, although the aMCI group performed better than the AD group. More specifically, AD patients remembered both remote and recent time periods worse than HOC, while the aMCI group differed significantly with HOC only for recent memory [15]; in contrast, other research [16] demonstrated that personal semantic memory is compromised in aMCI patients in comparison with healthy elderly controls.

$\mathrm{AM}$ was found to be impaired in $\mathrm{AD}$ patients, and semantic retrieval was poorer in $\mathrm{AD}$ patients than in healthy controls and aMCI patients $[15,17]$. In addition, these results were also observed for autobiographical incidents (episodic) [15], but Barnabe only observed differences between $\mathrm{AD}$ patients and healthy controls [17]. This worse AM has shown different temporal profiles [4], with better retrieval being observed for old memories than for recent ones in $\mathrm{AD}$ when $\mathrm{AM}$ is evaluated as a global score (semantic and episodic AM grouped together) [16]. However, when considered alone, episodic memories tend 
to be impaired regardless of the time interval, whereas old semantic memories tend to be better preserved than recent ones [18]. It should be noted that the relative preservation of old semantic autobiographical memories occurs only for mild AD because with the progression of the disease, these memories also become prone to substantial loss. It can be argued that representations of personally relevant knowledge that became part of semantic memories earlier in life are more strongly integrated in the brain, better consolidated, and therefore, less degraded by AD [19]. The episodic memory findings suggest that the more frequently retrieved autobiographical memories generally become more independent from the hippocampal complex, and might thus be better protected from early hippocampal damage related to $\mathrm{AD}[20]$.

Evidence shows a deterioration in autobiographical memory at the onset of the neurodegenerative disease typical of dementia, but not how the deterioration progresses toward more severe symptoms. To our knowledge, few longitudinal studies $[2,14,21]$ have contrasted the evolution of AM impairments, even though it is important to know how the deterioration will advance in order to determine what aspects of episodic and semantic memory will be affected. To discover the evolution of autobiographical memory, we studied groups of healthy older controls, aMCI, and AD for 18 months. We compared the three groups at baseline and in the follow-up-first for episodic autobiographical memory, and second for semantic memory-to discover the differences in their performance. Moreover, the longitudinal evolution of each group was analyzed for each type of memory in order to find out the possible changes after eighteen months.

\section{Materials and Methods}

\subsection{Participants}

Initially, 91 subjects participated in the study, although only 59 completed it; only older adults over 65 years old (range 65-87, average 75.94) who completed the cognitive and neuropsychological assessment at baseline (T1) and follow-up (T2) were selected for this study on AM. Participants were classified into three groups: healthy older controls (HOC; $n=26$ ), amnestic Mild Cognitive Impairment (aMCI; $n=17$ ), and dementia-type Alzheimer (AD; $n=16)$ (see Table 1 for sociodemographic).

Table 1. Mean scores (and standard deviations) for demographic and neuropsychological variables obtained at Time 1 and Time 2 by the different study groups.

\begin{tabular}{|c|c|c|c|c|c|c|c|c|}
\hline \multirow[t]{2}{*}{ Variables } & \multicolumn{2}{|c|}{$\begin{array}{l}\text { a. HOC } \\
(n=26)\end{array}$} & \multicolumn{2}{|c|}{$\begin{array}{l}\text { b. aMCI } \\
(n=17)\end{array}$} & \multicolumn{2}{|c|}{$\begin{array}{l}\text { c. } \mathrm{AD} \\
(n=16)\end{array}$} & \multicolumn{2}{|c|}{$\begin{array}{l}\text { Significant Differences } \\
(p<0.05)\end{array}$} \\
\hline & T1 & $\mathrm{T} 2$ & T1 & $\mathrm{T} 2$ & T1 & T2 & T1 & T2 \\
\hline Age & \multicolumn{2}{|c|}{$74.53(4.90)$} & \multicolumn{2}{|c|}{$77.35(4.76)$} & \multicolumn{2}{|c|}{$77.07(4.54)$} & \multicolumn{2}{|c|}{$a=b=c$} \\
\hline Gender & \multicolumn{2}{|c|}{$10 / 16$} & \multicolumn{2}{|c|}{$6 / 11$} & \multicolumn{2}{|c|}{$5 / 11$} & \multicolumn{2}{|c|}{ 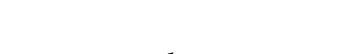 } \\
\hline Education & \multicolumn{2}{|c|}{2.78} & \multicolumn{2}{|c|}{2.47} & \multicolumn{2}{|c|}{2.50} & \multicolumn{2}{|c|}{$\mathrm{a}=\mathrm{b}=\mathrm{c}$} \\
\hline GDS & 1.21 & 1.1 & 2.29 & 2.52 & 3.35 & 3.71 & $\mathrm{a}<\mathrm{b}<\mathrm{c}$ & $\mathrm{a}<\mathrm{b}<\mathrm{c}$ \\
\hline CES-D & 5.28 & 5.9 & 9.01 & 8.71 & 9.21 & 9.14 & $\mathrm{a}=\mathrm{b}=\mathrm{c}$ & $\mathrm{a}=\mathrm{b}=\mathrm{c}$ \\
\hline MMSE & 29.04 & 28.46 & 21.64 & 21.35 & 17.57 & 17.49 & $a>b>c$ & $a>b>c$ \\
\hline VFTC & 23.75 & 22.64 & 13.01 & 11.47 & 7.64 & 5.76 & $a>b>c$ & $a>b>c$ \\
\hline VFTP & 37.78 & 38.71 & 23.41 & 22.29 & 14.64 & 12.35 & $a>b>c$ & $a>b>c$ \\
\hline TAVEC-I & 53.28 & 56.53 & 27.78 & 25.35 & 15.85 & 13.71 & $a>b>c$ & $a>b>c$ \\
\hline TAVEC-D & 12.57 & 12.67 & 3.41 & 3.01 & 1.07 & 0.93 & $\mathrm{a}>(\mathrm{b}=\mathrm{c})$ & $a>(b=c)$ \\
\hline DSF & 8.18 & 8.07 & 7.46 & 7.21 & 5.64 & 4.98 & $(a=b)>c$ & $(a=b)>c$ \\
\hline DSB & 4.96 & 5.02 & 3.46 & 3.25 & 2.21 & 1.97 & $a>(b=c)$ & $a>(b=c)$ \\
\hline Rey-I & 34.39 & 34.42 & 24.37 & 24.37 & 16.71 & 10.35 & $a>b>c$ & $a>b>c$ \\
\hline Rey-D & 18.35 & 19.67 & 4.53 & 3.81 & 0.71 & 0.42 & $a>(b=c)$ & $a>(b=c)$ \\
\hline
\end{tabular}

HOC: healthy older controls; aMCI: amnesic mild cognitive impairment; AD: Alzheimer's disease; Gender (male/female); GDS: Global Deterioration Scale; CES-D: Center for Epidemiological Studies-depression scale; MMSE: Mini-Mental State Examination; VFTC: Verbal Fluency Test Categorical; VFTP: Verbal Fluency Test Phonological; TAVEC-I: Spain-Complutense Verbal Learning Test immediate; TAVEC-D: Spain-Complutense Verbal Learning Test delayed; DSF: Digit Span Forward; DSB: Digit Span Backward; Rey-I: Rey Immediate; Rey-D Rey Delayed. 
The general inclusion criteria for the study were: age $>65$, and no significant asymptomatic neurovascular disease, history of previous symptomatic stroke, medical condition significantly affecting the brain, motor-sensory defects, alcohol or drug abuse/dependence, serious psychiatric symptoms, or depressive symptomatology. Patients in the aMCI group met the diagnostic criteria specified by Petersen [22], and they were at levels 2 and 3 on the Global Deterioration Scale (GDS) [23]. The inclusion criteria for AD were: diagnosis of AD determined by the DSM-V [24] and reaching levels 3 and 4 on the Global Deterioration Scale [23].

Via the use of $G^{*}$ Power (G*Power 3.1.9.7, Düsseldorf, Germany) in computation, a priori statistical power analysis indicated a minimum total sample size of 66 for a power of 0.95 ( $\alpha=0.05 ; 1-\beta=0.95$; three groups; 2 measurements, and correlation among repeated measures of 0.5$)$ to detect a medium effect size $(f=0.25)$, in an $\mathrm{F}$ test of repeated measures for within-between interaction. Finally, with $n=59$, a sensitivity statistical power analysis indicated that this design is able to detect a medium effect size of $0.25(f=0.2628 ; \alpha=0.05$; $1-\beta=0.95)$.

\subsection{Procedure}

Clinical diagnosis was the end result of an extensive evaluation, which included medical history and physical and neuropsychological examinations, and was determined by consensus between the neurologists and a neuropsychologists (see Table 1 for neuropsychological data). Instruments for clinical assessment are described below. All participants (or close family members) gave written informed consent for participation in the study. The study was conducted according to the guidelines of the Declaration of Helsinki.

After the baseline assessment, the participants were informed that they would be called for a follow-up evaluation after about 18 months. A total of 91 participants initiated the study, met the inclusion criteria, and were assessed and assigned to the groups. Five HOC refused to participate in the follow-up; in the aMCI group, 13 dropped out of the study -6 refused to participate in the follow-up, and 7 were re-diagnosed with dementia during follow-up; in the AD group, 14 dropped out of the study -4 because of death, 7 due to a worse GDS score, and 3 refused to participate in the follow-up.

\subsection{Materials}

\subsubsection{General Cognitive Screening}

In addition to the GDS [23] and Center for Epidemiologic Studies-Depression Scale (CES-D) [25], all the participants completed a comprehensive battery of neuropsychological tests assessing the main cognitive domains. The CES-D was developed as a measure of depressive symptomatology in the general population. This scale has 20 elements included in previously validated depression scales. As a cut-off point, 16 is usually used, which indicates the presence of clinically significant symptoms.

The Mini-Mental State Examination (MMSE) [26] was used as an index of global cognitive functioning; the maximum score is 30 points. Language ability was assessed using the Categorical and Phonological fluency subtests of the Revised Barcelona Test (TBR) [27]. Verbal memory (short-term recall and delayed recall) was assessed using the Spain-Complutense Verbal Learning Test (TAVEC) [28], a list of 16 words from four different categories (kinds of fruit, spices, items of clothing, and tools) are presented orally five times to the participants; after each presentation, subjects are assessed on the number of words remembered correctly. Then, after a $20 \mathrm{~min}$ period, subjects' delayed recall is assessed. Attention and working memory were tested using Digit Span forwards and backwards [29]. The copy and delayed recall of the Rey Complex Figure [30] were used as measures of visuospatial construction and non-verbal anterograde memory, respectively.

\subsubsection{Assessment of Autobiographical Memory}

The Autobiographical Memory Interview (AMI) [31] is a semi-structured interview used to assess memory retrieval in two domains: personal semantic and autobiograph- 
ical incidents that are considered episodic. Questions about personal semantic content (involving retrieval of personal facts from one's past life) and autobiographical incidents (involving retrieval of episodes or incidents from one's past) are chosen to evoke memories from three periods (childhood, early adult life, and recent life).

In the Personal Semantics section, the subject is asked to recall information and the scores vary from 0 to 2 depending on the quality of the memory (better memory, better score). Subjects can obtain a maximum of 21 points in each of the three major periods, and 63 points in the whole test; in this section, the AMI offers alternative questions to facilitate responses in people with different circumstances and contexts. In the Autobiographical Incident section, which evaluates episodic memory, subjects should evoke three incidents per period. The score depends on the descriptive richness of the incident and its specificity in time and place. If the memory specifies the temporal moment and place, it obtains 3 points; if it is not very specific and does not include the time or place, it obtains 2 points; if it is a vague memory, it is awarded 1 point; and finally, if there is no answer or the answer is based on a semantic memory, 0 points are awarded; a maximum of 27 points may be attained in the test. Two independent judges individually assessed the responses to calculate inter-judge reliability; ratings were correlated using Pearson's correlations and obtained $r>0.83$, which guarantees reliable correction.

\subsubsection{Follow-Up Assessment}

Fifty-nine participants underwent a follow-up assessment in which they were readministered the AMI as well as the neuropsychological tests. The average time between baseline and follow-up was 18.1 months (range 16 to $19 ; S D=0.78$ ) and did not differ significantly between the groups.

\subsection{Data Analysis}

Two mixed ANOVAs with 3 groups (healthy older control, aMCI, and AD; between subjects) $\times 2$ times (T1 and T2; within subjects) were applied to two types of memory (episodic or semantic). Simple-effects tests were applied to analyze the significant interactions. All analyses were carried out using the SPSS 21 (IBM Corp, Armonk, NY, USA) statistical package.

\section{Results}

A mixed ANOVA was performed with three groups (HOC, aMCI, and AD, betweensubjects) $\times 2$ times (T1 and T2; within subjects) on the episodic autobiographical memory scores. Results showed significant main effects for both the time $(F(1,56)=29.32 ; p<0.001$; $\left.\eta^{2}=0.344\right)$ and group $\left(F(2,56)=66.01 ; p<0.001 ; \eta^{2}=0.213\right)$, as well as the interaction $\left(F(2,56)=13.38 ; p<0.001 ; \eta^{2}=0.323\right.$; see Figure 1$)$. Given the significant interaction, two simple-effects tests were applied. Regarding the differences between groups at each time, the differences were significant at baseline $\left(F(2,56)=30.88 ; p<0.001 ; \eta^{2}=0.525\right)$, with greater recall in healthy older adults than in $\operatorname{aMCI}(p=0.010)$ and $\mathrm{AD}(p<0.001)$, and greater recall in aMCI than in $\mathrm{AD}(p<0.001)$. At the follow-up assessment, the between-groups comparison also showed significant differences $\left(F(2,56)=95.25 ; p<0.001 ; \eta^{2}=0.773\right)$, with greater recall in healthy older adults than in aMCI $(p<0.001)$ and $\mathrm{AD}(p<0.001)$, and greater recall in aMCI than in $\mathrm{AD}(p<0.001)$. Regarding the differences between times for each group, the simple-effects test showed a non-significant effect in the healthy older adult group $\left(F(1,56)=0.72 ; p=0.399 ; \eta^{2}=0.013\right)$, but a significant decrease in both the $\operatorname{aMCI}$ group $\left(F(1,56)=25.41 ; p<0.001 ; \eta^{2}=0.312\right)$ and the $\operatorname{AD~group}(F(1,56)=18.31$; $\left.p<0.001 ; \eta^{2}=0.246\right)$. 

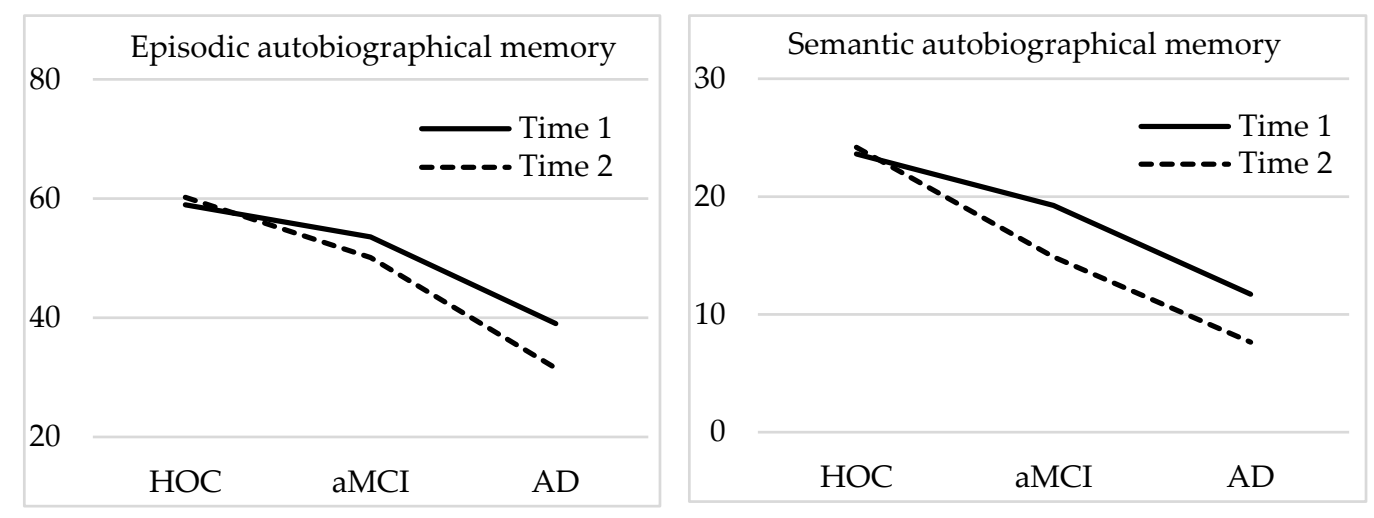

Figure 1. Mean scores for semantic and episodic autobiographical memory obtained at Time 1 and Time 2 by the different study groups.

With regard to the semantic autobiographical memory scores, the mixed ANOVA showed significant main effects for both the time $\left(F(1,56)=15.38 ; p<0.001 ; \eta^{2}=0.216\right)$ and group $\left(F(2,56)=54.59 ; p<0.001 ; \eta^{2}=0.213\right)$, and a significant time $x$ group interaction $\left(F(2,56)=10.19 ; p<0.001 ; \eta^{2}=0.661\right.$; see Figure 1$)$. Given the significant interaction, two simple-effects tests were applied. Regarding the differences between groups in each time, the differences were significant at baseline $\left(F(2,56)=33.82 ; p<0.001 ; \eta^{2}=0.547\right)$, with no difference between healthy older adults and aMCI, but greater recall in healthy older adults than in $\mathrm{AD}(p<0.001)$, and greater recall in $\mathrm{aMCI}(p<0.001)$ than in $\mathrm{AD}$ (Figure 1$)$. At the follow-up assessment, the between-groups comparison also showed significant differences $\left(F(2,56)=59.78 ; p<0.001 ; \eta^{2}=0.547\right)$, with greater recall in healthy older adults than in aMCI $(p<0.001)$ and $\mathrm{AD}(p<0.001)$, and greater recall in aMCI than in $\mathrm{AD}$ $(p<0.001)$. Regarding the differences between times for each group, the simple-effects test showed a non-significant effect in the healthy older adult group $(F(1,56)=1.19 ; p=0.280$; $\left.\eta^{2}=0.021\right)$, but a significant decrease in both the aMCI group $(F(1,56)=5.75 ; p=0.022$; $\left.\eta^{2}=0.091\right)$ and the $\operatorname{AD~group}\left(F(1,56)=21.23 ; p<0.001 ; \eta^{2}=0.275\right)$.

\section{Discussion}

The results obtained complement previous findings, confirming that episodic AM was worse when the pathology was more serious; this pattern observed at baseline was maintained at the follow-up. Regarding the longitudinal findings, no significant change was observed in the scores of the healthy controls, but the aMCI and AD subjects showed a significant decrease in their scores on episodic and semantic autobiographical memory.

As the results show, there is a pattern of episodic AM deterioration in the groups of patients as compared to the healthy controls that is maintained in the two time points evaluated, suggesting that when the pathology became more severe, this deterioration was also greater. Some studies have found that episodic memory is impaired with normal aging, finding differences in episodic memory between young and older adults [32,33]. Furthermore, this deterioration in episodic memory is also observed in those studies that compare middle-aged adults with older adults, finding a gradual and progressive deterioration of episodic memory as the person gets older $[4,18]$. In our study, no deterioration in episodic memory was observed between times in the group of healthy older adults, since the time period was only 18 months. Perhaps, if we could compare their current scores with those obtained years ago, we would have observed this pattern. Regarding the aMCI group, a decrease in episodic recall was observed, although this decrease was not as pronounced as that observed in the $\mathrm{AD}$ group. The reduction in episodic autobiographical memory in aMCI could be related to the dysfunction of neocortical structures [12]. In AD, one of the earliest symptoms is a deficit in anterograde episodic memory [34], followed by a retrograde impairment [35]. Moreover, in patients with aMCI and AD, the MTL, particularly the hippocampus and entorhinal cortex, has been found to undergo early volume loss [35], which is associated with a decline in both anterograde and retrograde 
memory performance. Therefore, the differences observed in episodic AM between the groups of patients could be due to the fact that in aMCI, MTL volume lies between that of healthy elderly people and patients with AD [36].

In semantic AM, two results stand out when comparing the groups. While healthy controls and $\mathrm{aMCI}$ at baseline showed differences from the AD group, in the follow-up, differences were obtained between healthy controls and aMCI, and between both groups and $\mathrm{AD}$. The results obtained in aMCI could explain the contradictions found in some studies. Some studies did not detect any impairment in autobiographical semantic memory in healthy older adults [37] and aMCI patients [12]. A possible explanation for the maintenance of semantic memory in the aMCI group could be that the details provided by the participants were not linked to a spatial or temporal context, and therefore did not depend on the hippocampus. Furthermore, this result suggests that neural systems that support these memories, such as the lateral temporal cortex, may remain relatively intact in aMCI [12]. In contrast, other studies demonstrated that personal semantic memory is compromised in aMCI in comparison with healthy elderly controls [16] and pointed to a decline in semantic autobiographical memory for recent memories [15]. As the authors have indicated, these differences in the previous findings may be due to differences in the patient populations studied. When studying the same group at two different time points, it has been observed that both results can make sense, and the deterioration in this type of memory in these patients would be confirmed. This result demonstrates the semantic $\mathrm{AM}$ deterioration in the aMCI group eighteen months after the first evaluation and suggests that a decline in autobiographical memory starts as soon as the consolidation of autobiographical information is disturbed by hippocampal damage [15]. Hippocampal volume change gradually intensifies on a continuum, ranging from healthy elderly individuals exhibiting a fairly intact hippocampal structure to aMCI individuals experiencing smaller hippocampal subfields, and finally, to AD patients presenting severe atrophy in all the hippocampal subfields [38]. A possible explanation for our findings is that the initial consolidation of personal semantic facts depends on the hippocampus; therefore, it is also susceptible to early hippocampal damage [15]. In addition, these results are corroborated by the longitudinal analysis of the groups, where a significant deterioration was found in both groups of patients.

Some limitations must be indicated. First, the sizes of the sample groups were unequal, with a difference in the number of participants in the healthy and patient groups. Second, we did not correlate the autobiographical memory function with the subjects' radiological findings, volumetric assessment of the hippocampus, or functional imaging study. Finally, it should be noted that the instruments for evaluating AM components differ across studies, making it difficult in some cases to compare the results. In this regard, it would be interesting to standardize the evaluation instruments to facilitate comparisons. In addition, it should be noted that when using the Personal Semantics and Autobiographical Incident scores as a combination of the three time points evaluated, it is difficult to compare recent memories and old memories; in future studies, it would be interesting to compare both types of memories in order to know if there is a differential influence on their consolidation.

In summary, the present study showed that autobiographical memory was impaired in patients with $\mathrm{AD}$ and $\mathrm{aMCI}$. This deterioration was found mainly in episodic memory in both groups. However, while the deterioration in semantic memory was confirmed in $\mathrm{AD}$, a pattern was observed in the aMCI group that evolved toward deterioration over a period of eighteen months.

Author Contributions: Conceptualization, J.C.M.; data curation, E.S., I.D., M.A. and E.R.; funding acquisition, J.C.M.; investigation, E.R. and I.D.; methodology, A.P.; resources, E.S. and I.D.; software, A.P.; writing—original draft, E.S., I.D., M.A. and E.R.; writing—review and editing, J.C.M. and A.P. All authors have read and agreed to the published version of the manuscript.

Funding: This work was supported by the Spanish Ministerio de Ciencia, Innovación y Universidades (Spain) [Grant PID2019-103956RB-I00]. 
Institutional Review Board Statement: The study was conducted according to the guidelines of the Declaration of Helsinki.

Informed Consent Statement: Informed consent was obtained from all subjects involved in the study.

Data Availability Statement: The data presented in this study are available on request to the authors. The data are not publicly available due to privacy reasons.

Conflicts of Interest: The authors declare no conflict of interest.

\section{References}

1. Pitarque, A.; Meléndez, J.C.; Sales, A.; Mayordomo, T.; Satorres, E.; Escudero, J.; Algarabel, S. The effects of healthy aging, amnestic mild cognitive impairment, and Alzheimer's disease on recollection, familiarity and false recognition, estimated by an associative process-dissociation recognition procedure. Neuropsychologia 2016, 91, 29-35. [CrossRef]

2. Irish, M.; Landin-Romero, R.; Mothakunnel, A.; Ramanan, S.; Hsieh, S.; Hodges, J.R.; Piguet, O. Evolution of autobiographical memory impairments in Alzheimer's disease and frontotemporal dementia-A longitudinal neuroimaging study. Neuropsychologia 2018, 110, 14-25. [CrossRef]

3. Fivush, R.; Habermas, T.; Waters, T.E.; Zaman, W. The making of autobiographical memory: Intersections of culture, narratives and identity. Int. J. Psychol. 2011, 46, 321-345. [CrossRef]

4. Piolino, P.; Desgranges, B.; Benali, K.; Eustache, F. Episodic and semantic remote autobiographical memory in ageing. Memory 2002, 10, 239-257. [CrossRef] [PubMed]

5. Tulving, E. Episodic memory and autonoesis: Uniquely human. In The Missing Link in Cognition: Origins of Self-Reflective Consciousness; Herbert, S., Metcalfe, J., Eds.; Oxford University Press: New York, NY, USA, 2005; pp. 3-56.

6. Baddeley, A. The concept of episodic memory. Philos. Trans. R. Soc. Lond. Ser. B Biol. Sci. 2001, 356, 1345-1350. [CrossRef]

7. Maguire, E.A. Neuroimaging studies of autobiographical event memory. Philos. Trans. R. Soc. Lond. Ser. B Biol. Sci. 2001, 356, 1441-1451. [CrossRef] [PubMed]

8. Svoboda, E.; McKinnon, M.C.; Levine, B. The functional neuroanatomy of autobiographical memory: A meta-analysis. Neuropsychologia 2006, 44, 2189-2208. [CrossRef]

9. Piolino, P.; Desgranges, B.; Eustache, F. Episodic autobiographical memory over the course of time: Cognitive, neuropsychological and neuroimaging findings. Neuropsychologia 2009, 47, 2314-2329. [CrossRef] [PubMed]

10. Ford, J.H.; Rubin, D.C.; Giovanello, K.S. Effects of task instruction on autobiographical memory specificity in young and older adults. Memory 2014, 22, 722-736. [CrossRef]

11. Masdeu, J.C.; Zubieta, J.L.; Arbizu, J. Neuroimaging as a marker of the onset and progression of Alzheimer's disease. J. Neurol. Sci. 2005, 236, 55-64. [CrossRef]

12. Murphy, K.J.; Troyer, A.K.; Levine, B.; Moscovitch, M. Episodic, but not semantic, autobiographical memory is reduced in amnestic mild cognitive impairment. Neuropsychologia 2008, 46, 3116-3123. [CrossRef]

13. Meléndez, J.C.; Escudero, J.; Satorres, E.; Pitarque, A. Type of memory and emotional valence in healthy aging, mild cognitive impairment, and Alzheimer's disease. Psicothema 2019, 31, 60-65. [CrossRef]

14. Berna, F.; Schönknecht, P.; Seidl, U.; Toro, P.; Schröder, J. Episodic autobiographical memory in normal aging and mild cognitive impairment: A population-based study. Psychiatry Res. 2012, 200, 807-812. [CrossRef] [PubMed]

15. Leyhe, T.; Müller, S.; Milian, M.; Eschweiler, G.W.; Saur, R. Impairment of episodic and semantic autobiographical memory in patients with mild cognitive impairment and early Alzheimer's disease. Neuropsychologia 2009, 47, 2464-2469. [CrossRef] [PubMed]

16. Irish, M.; Lawlor, B.A.; O'Mara, S.M.; Coen, R.F. Exploring the recollective experience during autobiographical memory retrieval in amnestic mild cognitive impairment. J. Int. Neuropsychol. Soc. 2010, 16, 546-555. [CrossRef] [PubMed]

17. Barnabe, A.; Whitehead, V.; Pilon, R.; Arsenault-Lapierre, G.; Chertkow, H. Autobiographical memory in mild cognitive impairment and Alzheimer's disease: A comparison between the Levine and Kopelman interview methodologies. Hippocampus 2012, 22, 1809-1825. [CrossRef]

18. Irish, M.; Hornberger, M.; Lah, S.; Miller, L.; Pengas, G.; Nestor, P.J.; Hodges, J.R.; Piguet, O. Profiles of recent autobiographical memory retrieval in semantic dementia, behavioural-variant frontotemporal dementia, and Alzheimer's disease. Neuropsychologia 2011, 49, 2694-2702. [CrossRef]

19. El Haj, M.; Antoine, P.; Nandrino, J.L.; Kapogiannis, D. Autobiographical memory decline in Alzheimer's disease, a theoretical and clinical overview. Ageing Res. Rev. 2015, 23, 183-192. [CrossRef]

20. Müller, S.; Mychajliw, C.; Reichert, C.; Melcher, T.; Leyhe, T. Autobiographical memory performance in Alzheimer's disease depends on retrieval frequency. J. Alzheimers Dis. 2016, 52, 1215-1225. [CrossRef]

21. Maguire, E.A.; Kumaran, D.; Hassabis, D.; Kopelman, M.D. Autobiographical memory in semantic dementia: A longitudinal fMRI study. Neuropsychologia 2010, 48, 123-136. [CrossRef]

22. Petersen, R.C. Mild cognitive impairment as a diagnostic entity. J. Intern. Med. 2004, 256, 183-194. [CrossRef] [PubMed]

23. Reisberg, B.; Ferri, S.H.; de Leon, M.J.; Crook, T. The Global Deterioration Scale for assessment of primary degenerative dementia. Am. J. Psychiatry 1982, 139, 1136-1139. [CrossRef] 
24. American Psychiatric Association. Diagnostic and Statistical Manual of Mental Disorders; American Psychiatric Association: Washington, DC, USA, 2013.

25. Radloff, L.S. The CES-D scale a self-report depression scale for research in the general population. Appl. Psychol. Meas. 1977, 1, 385-401. [CrossRef]

26. Folstein, M.; Folstein, S.; Mc Hugh, P. Mini Mental State. A practical method for grading the cognitive state of patients for the clinician. J. Psychiatr. Res. 1975, 12, 189-198. [CrossRef]

27. Peña-Casanova, J. Test Barcelona Revisado. Normalidad, Semiología y Patologías Neuropsicológicas. [Barcelona Test Revised. Normality, Semiology and Neuropsychological Pathologies]; Masson: Barcelona, Spain, 2005.

28. Benedet, M.J.; Alejandre, M.A. Test de Aprendizaje Verbal España Complutense [Spanish Verbal Learning Test]; TEA Ediciones: Madrid, Spain, 1998.

29. Wechsler, D. WAIS-III.; Psychological Corporation: San Antonio, TX, USA, 1997.

30. Rey, A. Test de Copia y Reproducción de Memoria de Figuras Geométricas Complejas [Copy and Reproduction of Complex Geometric Figures from Memory Test]; TEA Ediciones: Madrid, Spain, 1999.

31. Kopelman, M.D.; Wilson, B.A.; Baddeley, A.D. The Autobiographical Memory Interview; Thames Valley Test Company: Bury St. Edmunds, UK, 1990.

32. Piolino, P.; Coste, C.; Martinelli, P.; Macé, A.L.; Quinette, P.; Guillery-Girard, B.; Belleville, S. Reduced specificity of autobiographical memory and aging: Do the executive and feature binding functions of working memory have a role? Neuropsychologia $\mathbf{2 0 1 0}$ 48, 429-440. [CrossRef]

33. St Jacques, P.L.; Levine, B. Ageing and autobiographical memory for emotional and neutral events. Memory 2007, 15, 129-144. [CrossRef]

34. Spaan, P.E.; Raaijmakers, J.G.; Jonker, C. Alzheimer's disease versus normal ageing: A review of the efficiency of clinical and experimental memory measures. J. Clin. Exp. Neuropsychol. 2003, 25, 216-233. [CrossRef]

35. Donix, M.; Brons, C.; Jurjanz, L.; Poettrich, K.; Winiecki, P.; Holthoff, V.A. Overgenerality of autobiographical memory in people with amnestic mild cognitive impairment and early Alzheimer's disease. Arch. Clin. Neuropsychol. 2009, 25, 22-27. [CrossRef]

36. Devanand, D.P.; Pradhaban, G.; Liu, X.; Khandji, A.; De Santi, S.; Segal, S.; Rusinek, H.; Pelton, G.H.; Honig, L.S.; Mayeux, R.; et al. Hippocampal and entorhinal atrophy in mild cognitive impairment prediction of Alzheimer disease. Neurology 2007, 68, 828-836. [CrossRef]

37. Meléndez, J.C.; Agusti, A.I.; Satorres, E.; Pitarque, A. Are semantic and episodic autobiographical memories influenced by the life period remembered? Comparison of young and older adults. Eur. J. Ageing 2018, 15, 417-424. [CrossRef]

38. Hirjak, D.; Wolf, R.C.; Remmele, B.; Seidl, U.; Thomann, A.K.; Kubera, K.M.; Schroder, J.; Maier-Hein, K.H.; Thomann, P.A. Hippocampal formation alterations differently contribute to autobiographic memory deficits in mild cognitive impairment and Alzheimer's disease. Hippocampus 2017, 27, 702-715. [CrossRef] [PubMed] 